\title{
Memórias de uma judia sefardita: reminiscências poéticas na Amazônia ${ }^{1}$
}

\author{
Memories of a Sephardic Jew: poetic reminiscenses in the Amazon
}

\author{
Alessandra F. CONDE DA SILVA* \\ Universidade Federal do Pará (UFPA)
}

\begin{abstract}
RESUMO: Este trabalho realiza um estudo sobre alguns poemas que aludem às memórias de infância, presentes no livro Sarandalhas (1967), de Mady Benoliel Benzecry, poetisa nascida em Manaus, de origem judaico sefardita. Neste percurso, procuramos deslindar as reminiscências como um ato de rememoração, no sentido benjaminiano, ou seja, o produto dessa rememoração, neste estudo, é tomado como reminiscências poéticas, recriadas ou reinterpretadas a partir do cadinho das imagens da infância da escritora amazonense. Neste sentido, Mady Benoliel Benzecry poetisa e pinta a gente amazônica: o caboclo, a vizinhança, a família judia. Tudo posto em um "Baú da infância", título de um de seus poemas. Samuel Benchimol (2008), Walter Benjamin (1987) e Jeanne Marie Gagnebin (2006), entre outros, nos forneceram amparo teórico.
\end{abstract}

PALAVRAS-CHAVE: Sarandalhas; Mady Benoliel Benzecry; Reminiscências poéticas.

ABSTRACT: This work proposes a study of some poems, which allude to childhood memories, in the book Sarandalhas (1967), by Mady Benoliel Benzecry, a poetess of Sephardic Jewish origin born in Manaus. Along our trajectory, we seek to unravel the reminiscences as an act of remembrance, as supported by W.Benjamin, in the sense that the product of this remembrance is taken as poetic reminiscences, recreated or reinterpreted from the crucible of the Amazonian writer's childhood images. In that regard, Mady Benoliel Benzecry poetically portrays and paints the Amazonian people: the caboclo, the neighborhood, the Jewish family. Everything is put in a "Baú da infância", title of one of her poems. Samuel Benchimol (2008), Walter

\footnotetext{
${ }^{1}$ Este artigo foi parcialmente publicado, como capítulo de livro, no livro Ecos Sefarditas: Judeus na Amazônia (2020), com o título "O 'Baú da infância' de Mady B. Benzecry: reminiscências poéticas". Nesta versão há acréscimos.

* Doutora em Letras e Linguística pela Universidade Federal de Goiás. Professor Adjunto da Universidade Federal do Pará. Vinculada à Faculdade de Letras (FALE) do Campus de Bragança -Pa. Coordenadora do projeto de pesquisa "Ecos sefarditas: judeus na Amazônia" e do NESA (Núcleo de Estudos sefarditas da Amazônia). E-mail: afcs77@ hotmail.com
}

Revista Moara, n. 56, vol. 1, ago-dez 2020 ISSN: 0104-0944

Recebido em 16/07/2020

Aceito em16/12/2020 
Benjamin (1987) and Jeanne Marie Gagnebin (2006), among others, will bring us theoretical support.

KEYWORDS: Sarandalhas; Mady Benoliel Benzecry; Poetic reminiscences

\section{Introdução}

A paraense Sultana Levy Rosenblatt não é a única figura feminina entre os escritores sefarditas amazônicos. Nesta categoria estão, além de Sultana Levy Rosenblatt, escritores nascidos ou radicados no território amazônico como Leão Pacífico Esaguy, Paulo Jacob, Marcos Serruya, Elias Salgado e Ilko Minev. A outra escritora é Mady Benoliel Benzecry, poetisa amazonense, nascida em 19 de fevereiro de 1933. Judia de origem sefardita, ela assenta-se como uma voz poética entre os escritores judeus na Amazônia. Mady Benzecry escreveu dois livros: De todos os crepúsculos, em 1964, e Sarandalhas, em 1967. Neste, a escritora demonstra talento literário, recebendo elogios de Jorge Amado e de Luís da Câmara Cascudo, conforme se veem nas orelhas do referido livro. O primeiro alude aos "seus altos voos", vaticinando sua brilhante carreira, conforme se cria acontecer. Além disso, o romancista louvou as recordações de infância da poetisa amazonense. O segundo destaca a sua genialidade e o seu excepcional lirismo nas loas destinadas à centenária cidade de Salvador.

Em Sarandalhas, as memórias de infância submergem com delicadeza e encanto. Mady Benzecry divide o seu livro em quatro seções: "A criação da Bahia", "Baú da Infância", "5 Cantilenas" e "Esparsas". No poema "Baú da Infância", surgem as imagens doces e intensas dos familiares do Eu lírico, sobretudo a do avô e da avó. O Eu lírico nesse poema é sentimental; procura perscrutar as emoções e as reminiscências empoeiradas, conforme se vê em "Poema-título", texto que antecede o "Baú da infância". A infância retratada no poema foi feliz, o que deixa o trabalho de rememoração prazeroso e idílico, quase mágico, porque lapsos e situações comuns recebem uma aura de beleza exemplar. As imagens rememoradas são postas em um locus amoenus, reconstruído no presente a partir das figuras passadistas.

Revista Moara, n. 56, vol. 1, ago-dez 2020 ISSN: 0104-0944 


\title{
10 "Baú da infância" e outros poemas: reminiscências poéticas
}

Walter Benjamin propõe alguns questionamentos sobre a relação entre o passado e o presente, sugerindo um "encontro secreto" entre as gerações de hoje e as de ontem. Para ele, "o passado traz consigo um índice misterioso que o impele à redenção. Pois não somos tocados por um sopro do ar que foi respirado antes? Não existem nas vozes que escutamos, ecos das vozes que emudeceram?" (BENJAMIN, 1987, p. 223). Tais encontros podem ser vistos nos poemas memorialísticos de Mady Benzecry. Rememorar é o que ela faz. Segundo Jeanne Marie Gagnebin (2006, p. 55), a rememoração,

\begin{abstract}
implica uma certa ascese da atividade historiadora que, em vez de repetir aquilo de que se lembra, abre-se aos brancos, aos buracos, ao esquecido e ao recalcado, para dizer, com hesitações, solavancos, incompletude, aquilo que ainda não teve direito nem à lembrança nem às palavras. A rememoração também significa uma atenção precisa ao presente, em particular a estas estranhas ressurgências do passado no presente, pois não se trata somente de não se esquecer do passado, mas também de agir sobre o presente. A fidelidade ao passado, não sendo um fim em si, visa à transformação do presente.
\end{abstract}

As imagens da incompletude e da incerteza, de coisas já esquecidas são retomadas em "Poema-título", conforme vê-se nos primeiros versos. Este texto pode ser visto como um poema introdutório ao "Baú da infância":

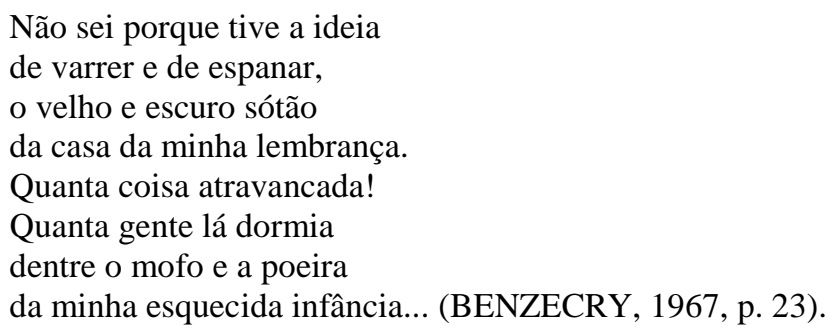

Nos versos finais, o Eu lírico consente em entrar no velho sótão, realocando emoções e lembranças:

\footnotetext{
Quase com medo o abri; e no sótão velho e escuro, da casa da minha lembrança, um som rangente ecoou, primeiro pulou vovô, Vovô! É você, vovô!? - Meu Deus! E emocionada, Revi, beijei e brinquei
} 
com a gente e com tanta coisa

da minha esquecida infância! (GRIFOS NOSSOS). (BENZECRY, 1967, 24).

Neste poema, o Eu lírico afirma brincar com as pessoas e "com tanta coisa" de sua infância. O produto dessa visitação ao passado, do encontro entre passado e presente, é um exercício de rememoração, de brincadeira com as imagens de ontem, não no sentido de desprezo ao passado. Ao contrário, este é cultuado, tendo o riso como preenchimento dos lapsos memorialísticos e enlevamento das imagens soçobradas ou esvanecidas pelo tempo. Estes tipos de imagem são nitidamente perceptíveis em "Baú da infância”. As histórias de família logram expressivo valor. De origem judaicomarroquina, o Eu lírico atesta que os vizinhos jamais os trataram com atitudes antijudaicas: "Embora judeus tivemos / (graças a Deus) bons vizinhos, / eram os padres capuchinhos / da igrejinha da praça" (BENZECRY, 1967, p. 26). Outros vizinhos são descritos com humor. O strep-tease da velha Anastácia finda com imprecações destinadas ao grupo familiar dos judeus, que sorrateiramente atocaiava a vizinha "feia e rabugenta", na janela do sobrado (BENZECRY, 1967, p. 25).

As raízes judaicas da família Benzecry têm na figura da avó Alegria singular expressão. Imigrante do Marrocos, a matriarca relembra com saudade da terra de seu nascimento: "Os quadros eram gravuras / marroquinas - "Nesta rua / eu morava" - e sem querer, / pobre vovó - suspirava" (BENZECRY, 1967, p. 29). Claramente, os versos aludem, poeticamente, à presença de imigrantes judeus sefarditas, vindos do Marrocos para a Amazônia, desde o século XIX.

Há, no entanto, outras histórias que foram sussurradas nas lembranças de Mady Benzecry. Algumas de suas poesias assemelham-se a contos postos em versos, como diz Marcos André sobre as poesias de Mady Benzecry (apud MARGUTTI, 2003, p. 66). Em "Baú da infância" há um forte apelo narrativo. A poetisa quer contar, ou melhor seria dizer, poetar histórias. A estrofe em que Conceição é citada, revela uma história quase silenciada. Conceição é uma indiazinha criada pela mãe do Eu lírico. Nas brincadeiras, as crianças sempre destinavam à Conceição o monstruoso papel dos alemães. O Eu lírico não tece juízo de valor contundente à guerra ou ao inimigo alemão, mas, parece-nos que, numa brincadeira de criança, o fazer poético empresta a uma judia, uma arma letal contra o assassino de sua etnia. Há um jogo de imagens sobrepostas. Conceição, ao mesmo tempo que representa o alemão, é, ela própria, representante da 
extinção de seu povo. Dois povos, dois destinos. No entanto, um é o carrasco e o outro é a vítima. Cabem às crianças subjugar o algoz alemão:

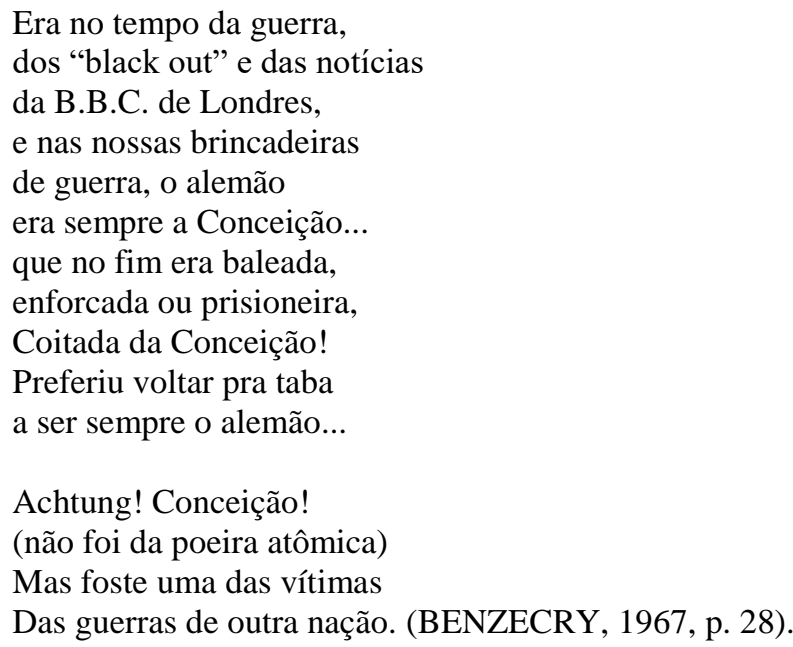

Neste poema, não há silêncio absoluto à barbárie alemã. Mas a denúncia necessita ser perscrutada. Há uma imagem poética delicada e plural que se presta a servir duas causas: uma assume figuração de simpatia à causa e denuncia o genocídio cultural indígena, outra assume uma voz de indignação, de resistência e de luta contra o nefasto regime nazista. Esta voz ecoa nos fazeres lúdicos das crianças, revelando como elas externaram a guerra e as suas monstruosidades. $\mathrm{O}$ que teriam elas internalizado? $\mathrm{O}$ que a elas foi dito sobre a guerra e os nazistas? o Eu lírico não responde a isso. Não entra no jogo dos adultos, da linguagem dos adultos. Apenas dá vida ao mundo infantil e à sua peculiar tradução sobre o episódio da guerra. E Conceição, transformada em imagem poética, foi vítima real e também ocasional. Restou à indiazinha o abraço de seu povo. A sobrevivente de duas guerras sai da história dos seus algozes.

Sussurradas chegaram, aos ouvidos do Eu lírico, as histórias de seu avô paterno. Sorrateiramente, a menina ouvia narrativas impróprias aos ouvidos infantis, que se desejavam inocentes:

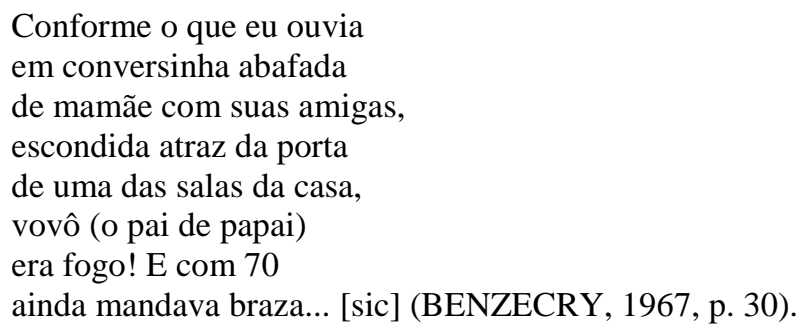

Revista Moara, n. 56, vol. 1, ago-dez 2020 ISSN: 0104-0944 
Nos versos seguintes que imprimem registro cômico, veem-se ecos da história dos judeus sefarditas na Amazônia, singrando os rios, como regatões, conquistando o sucesso financeiro e o sustento das famílias. Segundo Samuel Benchimol (2008, p. 85), "os judeus foram os primeiros regatões da região. Com suas embarcações, batelões e igarités, levavam mercadorias para vender nos distantes seringais". A morte do avô do Eu lírico, viajante sedutor dos rios amazônicos, trouxe à capital um cortejo de regatões e amantes apaixonadas. O humor, comum em Sarandalhas, arremata a história do prodigioso patriarca da família judia:

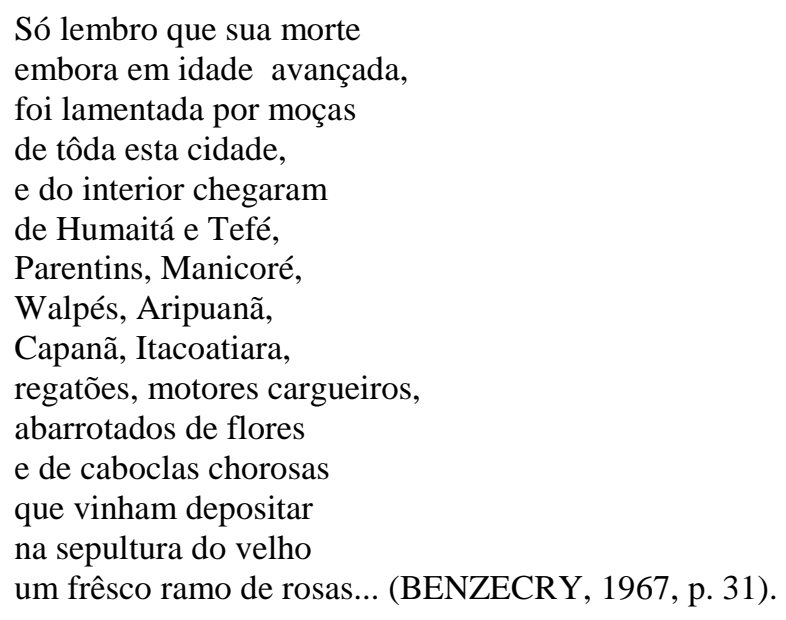

Mady Benzecry retoma esta temática em "O regatão (Bufarinheiro)". Neste poema, a vida simples e o trabalho árduo do regatão recebem tintas poéticas mágicas: um regalo musical para os seus dias de extremado labor vem com as graciosidades das narrativas míticas do atraente boto (BENZECRY, 1967, p. 72). Mas, ao mesmo tempo, seria o boto encantador o próprio bufarinheiro, "cantando pra elas ouví" (BENZECRY, 1967, p. 72)? O destino do regatão está selado: "e quando a noite aparece, / por onde quer que êle siga, / o Rio é a sua rua, / a lua é o seu farol” (BENZECRY, 1967, p. 73).

\section{Outros ecos na poesia de Mady Benzecry: a gente judia e a gente amazônica}

O outro livro de Mady Benzecry, De todos os crepúsculos, apresenta um teor grave e apaixonado. Em "Às dez horas de uma noite triste", o sensualismo e o desejo feminino reverberam com simplicidade. O cantar feminino, que muito lembra as 
cantigas medievais, é um apelo ao retorno do amante, após o intercurso amoroso. O registro paralelístico presente no primeiro verso de cada uma das três estrofes ("Não te demores, meu bem"!) e o arremate das estrofes, nos três versos finais ( ou seria o refrão, comum às cantigas de amigo?) embalam musicalmente os chamamentos íntimos do amor e do gozo:

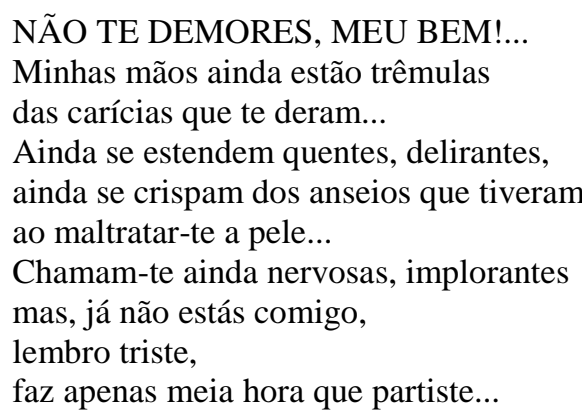

\section{NÃO TE DEMORES, MEU BEM!...}

Meus lábios permanecem entreabertos, como se ainda esmagados contra os teus, bebessem teu sangue nos desertos.

Ainda estão úmidos e sentem o jogo intenso que tua boca transportada de desejo, derramou na avidez de um infindo beijo... Mas já não estás comigo, lembro triste, faz apenas meia hora que partiste...

\section{NÃO TE DEMORES, MEU BEM!...}

Meu corpo ainda está como o deixaste, morno... todo marcado da volúpia com que o amaste...

No entanto, ainda deseja como um louco languidamente entregar-se, e pouco a pouco, matar a sede deste amor que não mataste! Mas, já não estás comigo, lembro triste, faz apenas meia hora que partiste!... (BENZECRY apud TELLES; KRÜGER, 2006, p. 2019-220).

Nesses versos reverberam volúpia e languidez amorosa. A ausência do amado conduz o Eu lírico a rememorar o amor vivido, sorvido. $\mathrm{O}$ ato deixa-o triste, carente, faminto, suplicante pelo retorno do seu "bem". No entanto, tais ecos amoroso não se veem em Sarandalhas, a não ser em "El Manchay-puito", poesia que muito se assemelha ao romance medieval, composição narrativa em verso. $\mathrm{O}$ amor proibido entre o padre Gaspar de Ângulo y Valdiviesco e a bela Anita Sielles são o assunto deste poema que flerta com a necrofilia e a morte. Longe do padre, Anita o conclama em um bilhete: "Mi alma está triste / y mi cuerpo desfallece. / Mi muero. / Ven, amado mio! / 
Tengo sed de un último beso" (BENZECRY, 1967, p. 88). O desejo do padre por Anita não se contém. O corpo inerte e despido seduz: "Dom Gaspar não resistiu:/ Dom Gaspar o profanou, Dom Gaspar o possuiu” (BENZECRY, 1967, p. 90).

Mady Benzecry, nos demais poemas, procura cantar as gentes da sua terra e não amores românticos. A Carmem doida, a velha Saúva, a Nêga Charuto, o Alfredo Lezo são personagens peculiares da infância da poetisa. Todas essas pessoas estão no "Baú da infância" que a poetisa manauara remexeu. As reminiscências buscam amparo nas coisas e pessoas simples. No poema "Em cada", de Sarandalhas, a poetisa esclarece os meandros do seu fazer poético, afeito ao simples, ao comum, ao pequeno, o que não significa falta de profundidade ou dispersão dos sentimentos:

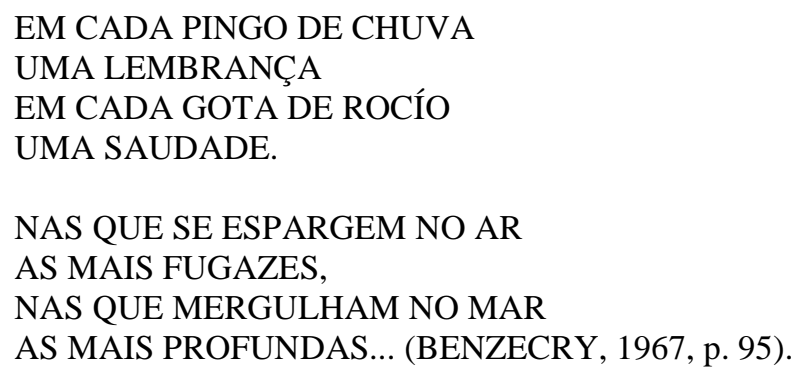

Em Nêga Charuto, há referências à fábrica de Isaac Sabá. Elias e David Salgado comentam que Isaac Sabá foi um dos investidores em exportação, criando "indústrias de beneficiamento de borracha, de castanha, com automatização do descascamento" (SALGADO, SALGADO, 2015, p. 25). Este industrial e outros dos seus coirmãos representam os judeus que lograram alta expressão no cenário econômico amazonense. Para Samuel Benchimol (1997, p. 53), Isaac Benayon Sabbá foi "o mais criativo empresário da região". O Eu lírico alude a isso e procura pôr em relevo as conquistas de um grupo que também é o seu. Nêga Charuto, a Petronila, fazia parte da infância de da poetisa, assim como o Isaac Sabá e suas empresas, também o fizeram. Segundo Michel Pollak (1989, p. 13), “tanto no nível individual como no nível do grupo, tudo se passa como se coerência e continuidade fossem comumente admitidas como os sinais distintivos de uma memória crível e de um sentido de identidade assegurados". A "Nêga" que ia de porta em porta recolher latas, vai também à "usina do seu Isaac Sabá" (BENZECRY, 1967, p. 46). Lá tem "tanta lata vazia” (BENZECRY, 1967, p. 46). A ideia de abundância e de prosperidade são sussurradas, como um tipo de cantoria da trabalhadora, enlevada pela concessão do "dotô" (BENZECRY, 1967, p. 46):

Revista Moara, n. 56, vol. 1, ago-dez 2020 ISSN: 0104-0944 


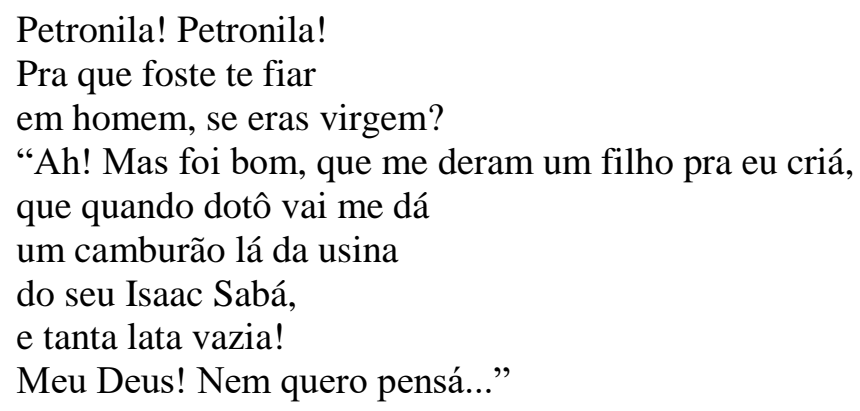

Se cantou a sua gente judia, cantou também a sua gente amazônida. Isso porque Mady Benzecry cantou, compôs música. Em Alegretto de Roçassine, da seção 5 cantilenas, Benzecry poetou uma canção, rememorando sabores da culinária local: "Da minha terra / Eu não sinto saudade, \{Bis / Mas sinto falta / Das comidas de lá á á á" (BENZECRY, 1967, p. 68). O tacacá, a macaxeira, o taperebá, o tucupi, “a tartarugada / na varanda do solar" (BENZECRY, 1967, p. 69) são cantados/evocados/rememorados por uma voz de contralto, em lá menor, atendendo a notações com andamento em alegreto, induzindo a uma interpretação ligeiramente alegre e rápida. Em notação, Mady Benzecry pontua: "(acompanhamento de caixa de fósforos sêca)" (BENZECRY, 1967, p. 68), embalando o ritmo numa percussão peculiar que se aproxima de um samba.

Além das inclinações poético-musicais, Mady Benoliel Benzecry dedicou-se também à pintura. Segundo Mario Margutti (2003, p. 105),

Poetisa-Música-Pintora, Mady é uma analogia viva do Amazonas. Tocando com suas artes a raiz do lirismo, ela se identifica com as lendas e feitiços da sua terra, evocando essências, amalgamando-as, ela própria, nos temas da sua arte, como num rito de celebração da memória, tornando-se uma espécie de sacerdotisa-guardiã das luxuriantes belezas amazônicas.

A artista plástica compôs quadros como Cidade flutuante, conforme se vê na imagem abaixo:

Revista Moara, n. 56, vol. 1, ago-dez 2020 ISSN: 0104-0944 
Cidade flutuante, de Mady B. Benzecry (apud MARGUTTI, 2003, p.37).

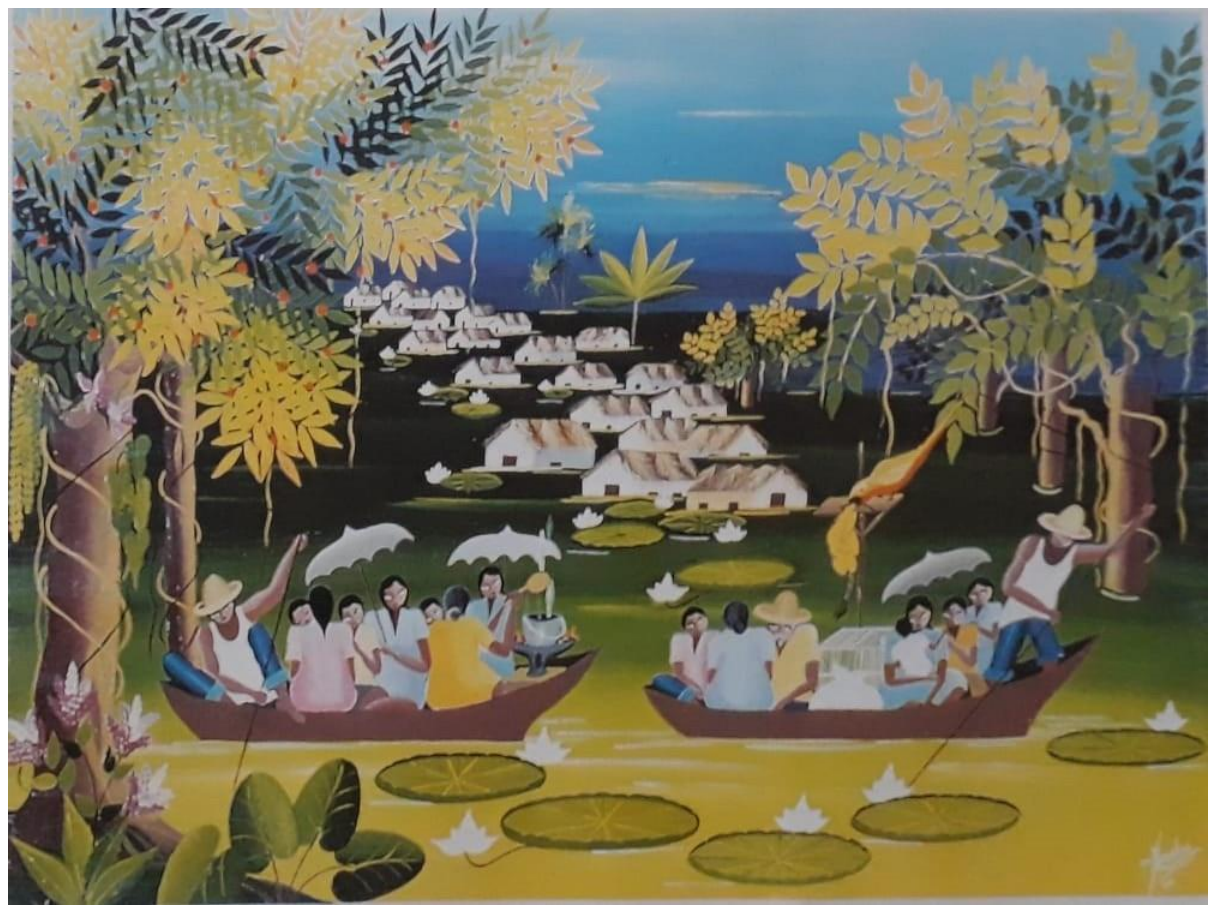

Na pintura, homens, mulheres e crianças são retratados tendo como escopo a vida ribeirinha. As embarcações, como as casas, ao fundo e em perspectiva linear, ganham relevo, proeminência, mostrando a vida em movimento, fluída, cercada por rios e floresta. No poema CIDADE FLUTUANTE, como na pintura homônima é o caboclo amazônica em sua lida no rio e na floresta que recebe mote principal:

Barracos de umbaúba, soalhos de acapú, esteios de acaricoara, telhados de ubuçú. Cortinas de céus bordados, tapetes de muriré, nimbados de espuma afloram, serão frotas de Noé?

No manto líquido negro, pardo, mesclado, barrento, vomitam estampidos horrendos dragões com asas de vento

e da garganta da noite escapam berros medonhos, elétricas espadanas serão Dante, os demônios?

Revista Moara, n. 56, vol. 1, ago-dez 2020 ISSN: 0104-0944 
Barracos de umbaúba, soalhos de acapu,

Veneza não tem teu verde, nem o canto do sanhaçu!

Mulheres pantagruélicas, misto de peixe e de gente que grega mitologia tem serva mais bela e ardente?

Caboclo forte e sem medo de guerras, de vendaval, que antiga couraça é mais rija que a tua, de animal?

O teu corcel é canoa, com rédeas de pixiúba, teu capacete de aço, é chapéu de carnaúba

E tu menino macrôptero, mais gordo que um matrinchão quantas estrelas tu fisgas nas pontas do teu arpão?

Barracos de umbaúba, soalhos de acapu, Veneza não tem teu verde, nem o canto o irapurú

Veneza não tem palmeiras, Veneza não tem teu azul, Veneza não tem tua gente nem o canto do Sanhaçu! (BENZECRY, 1967, p. 65-67).

A vida sobre as águas, o comércio, o trânsito das pequenas embarcações, a fauna e a flora exóticas mostram-se condições e atividades corriqueiras realizadas sobre o caudaloso rio. Uma mitologia amazônida é descrita com orgulho, capitalizando um jogo comparativo que alude às imagens presentes nos mitos gregos: homem/guerreiro/animal, mulher/peixe, menino alado/caçador, chapéu de carnaúba/capacete de aço, corcel/canoa. Mady Benzecry pinta quadros, canta e conta memórias e histórias, poetisa gentes, a judia e a cabocla: a gente amazônica.

Revista Moara, n. 56, vol. 1, ago-dez 2020 ISSN: 0104-0944 


\section{Considerações finais}

O Novo dicionário da língua portuguesa (1913) define "sarandalhas" como "f. Maravalhas. Restos. Fig. Gente ordinária, ralé”. A esses restos ou maravalhas tomamos como o fulcro das reminiscências da autora. Ela procura reorganizar e polir o passado, com humor e com graça, produzindo sarandalhas, poeticamente lembradas, cheiradas, ouvidas, olhadas e tocadas, como em "Poema-título": "da casa da minha lembrança/ [...] achei um velho baú / exalando um forte cheiro /[...] um som rangente ecoou, / [...] revi, beijei e brinquei” (BENZECRY, 1967, p. 23-24). Quanto às gentes? São as do melhor tipo. Gentes de verdade, ou como ela lembrou, cheirou, ouviu, olhou e tocou. Segundo Walter Benjamin (1987, p. 224), “articular historicamente o passado não significa conhecê-lo 'como ele de fato foi'. Significa apropriar-se de uma reminiscência, tal como relampeja no momento de um perigo". No caso de Mady Benoliel Benzecry, Sarandalhas são as suas reminiscências poéticas.

\section{REFERÊNCIAS}

BENCHIMOL, Samuel. Eretz Amazônia. Os judeus na Amazônia. Manaus: Valer, 2008.

BENCHIMOL, Samuel. Judeus no ciclo da borracha. In: Lewin, H. (org.) Judaísmo memória e Identidade. Rio de Janeiro: Programa de Estudos Judaicos/Departamento de Ciências Sociais/UERJ, Volume I, 1997, p. 47-54.

BENJAMIN, Walter. Magia e técnica, arte e política: ensaios sobre literatura e história da cultura. Trad. Sérgio Paulo Rouanet. São Paulo: Brasiliense, 1987 - (Obras escolhidas, vol. I).

BENZECRY, Mady Benoliel. Sarandalhas. Manaus: Editora Pongetti, 1967.

Revista Moara, n. 56, vol. 1, ago-dez 2020 ISSN: 0104-0944 
CÂNDIDO, Figueiredo. Novo dicionário da língua portuguesa. Lisboa: Livraria Clássica Editora, 1913.

GAGNEBIN, Jeanne Marie. Lembrar escrever esquecer. São Paulo: Editora 34, 2006.

MARGUTTI, Mário. Embaixadores da alma brasileira: vida e obra de Batista e Mady. Rio de Janeiro: Lucky, 2003.

POLLAK, Michael. Memória, esquecimento, silencio. Revista de Estudos Histórico. Rio de Janeiro, vol. 2, n. 3, 1989.

TELlES, Tenório; KRÜGER, Frederico (org.). Poesia e Poetas do Amazonas. Manaus: Editora Valer, 2006.

Revista Moara, n. 56, vol. 1, ago-dez 2020 ISSN: 0104-0944 